\title{
Preliminary findings of a novel measure of driving behaviors in Veterans with comorbid TBI and PTSD
}

\author{
Elizabeth K. Whipple, MS; ${ }^{1-2 *}$ Maria T. Schultheis, PhD; ${ }^{1}$ Keith M. Robinson, MD $^{2-3}$ \\ ${ }^{1}$ Department of Psychology, Drexel University, Philadelphia, PA; ${ }^{2}$ Corporal Michael J. Crescenz Department of Veter- \\ ans Affairs Medical Center, Philadelphia, PA; ${ }^{3}$ Department of Physical Medicine and Rehabilitation, Perelman School \\ of Medicine, University of Pennsylvania, Philadelphia, PA
}

\begin{abstract}
Veterans of the military operations in Iraq and Afghanistan are at an elevated risk of driving-related accidents and fatalities compared with civilians. Combat exposure, military driving training, risk-seeking, traumatic brain injury (TBI), and posttraumatic stress disorder (PTSD) are all factors associated with driving-related risk. However, few empirical studies have observed driving patterns in this population, and the influence of these contributing factors remains unclear. This study utilized a novel self-report measure to assess driving behaviors, driving-related anxiety, and emotional experiences of military Veterans who have returned to civilian driving. This questionnaire was completed by 23 combat Veterans diagnosed with comorbid TBI and PTSD and 10 nondisabled combat Veterans. Drivers with TBI and PTSD reported more frequent high-risk driving behaviors and higher levels of anxiety while driving in certain situations than nondisabled combat Veterans. These preliminary findings highlight the importance of studying on-the-road situations and cues that produce anxiety in Veterans, particularly those with TBI and PTSD. A greater understanding of driving-related anxiety is needed to inform targeted and effective interventions for unsafe driving in Veterans.
\end{abstract}

Key words: Afghanistan, anxiety, combat, deployment, driving, Iraq, motor vehicle accidents, posttraumatic stress disorder, traumatic brain injury, Veterans.

\section{INTRODUCTION}

Combat Veterans of Iraq and Afghanistan (Operation Iraqi Freedom [OIF], Operation Enduring Freedom [OEF], and Operation New Dawn [OND]) may be at higher risk of motor vehicle accidents (MVAs) than civilians [1]. Data suggest that post-9/11 military Veterans have difficulties readjusting to civilian driving patterns after returning home from deployment [2-3]; deployment history is associated with increased risky driving behavior and MVAs [4], and combat exposure may increase risk-taking propensity [5]. Moreover, the prevalence of traumatic brain injury (TBI) and posttraumatic stress disorder (PTSD) in the post-9/11 combat Veteran population appears to increase driving difficulties [6-8].

\footnotetext{
Abbreviations: IED = improvised explosive device, MVA = motor vehicle accident, OEF = Operation Enduring Freedom, OIF = Operation Iraqi Freedom, OND = Operation New Dawn, PTSD = posttraumatic stress disorder, $\mathrm{TBI}=$ traumatic brain injury, VA = Department of Veterans Affairs, VAMC $=$ Department of Veterans Affairs medical center, VDQ = Veteran Driving Questionnaire.

*Address all correspondence to Elizabeth $\mathrm{K}$. Whipple, MS; Department of Psychology, Drexel University, Stratton Hall 123, 3141 Chestnut St, Philadelphia, PA 19104; 215-895-6105; fax: 215-895-4930. Email: elizabeth.k.whipple.mil@mail.mil http://dx.doi.org/10.1682/JRRD.2015.09.0172
} 
Both TBI and PTSD have been shown independently to contribute to driving difficulties in civilian samples. A recent survey of adult drivers found that those with a lifetime history of TBI have significantly higher odds of involvement in aggressive driving and serious MVAs within the previous 12 mo when compared to non-TBI drivers [9]. TBI can affect many areas of cognition necessary for safe driving, including planning, inhibition, attentional allocation, insight, memory, and information processing speed [10]. Moreover, TBI can result in physical symptoms (e.g., headaches, blurred vision, photophobia) that can challenge safe driving [11]. PTSD can also compromise cognitive function in areas required for safe driving (e.g., attention, concentration, executive functioning) [7,12]. Related to this, it has been shown that individuals with anxiety disorders (e.g., PTSD, social anxiety, panic disorder) possess a cognitive processing bias in which they perceive neutral stimuli as negatively valenced and thus selectively attend to threatening stimuli [13]. This cognitive bias may have serious consequences on the road, where countless stimuli compete for attention, particularly when combined with executive functioning and processing speed deficits.

Driving requires the ability to simultaneously attend to multiple aspects of the environment, repeatedly make instantaneous decisions, accurately select and divide attention, consistently retain emotional control, and continuously reevaluate a situation. Therefore, the cumulative cognitive and emotional deficits seen in TBI and PTSD can quickly and significantly affect a driver's safety. Veterans with comorbid TBI and PTSD may perceive a benign or low-risk road environment (e.g., driving under an overpass) as more threatening or dangerous than a civilian driver would, potentially leading to overreactive behaviors and driving errors or avoidance.

These observations have been supported by prior literature on Veterans with PTSD, which has shown that post-9/11 Veterans with PTSD are more likely than those who screen negative for PTSD to report aggressive driving and more persistent driving problems [6,14], and they are four times more likely to report anxiety and hyperarousal on the road [4]. Amick et al. also reported that combat Veterans with comorbid PTSD and mild TBI make more critical errors while driving in a simulated environment than nondisabled control subjects [6]. Collectively, these data point to a relationship between heightened anxiety and an increased risk for driving errors.
Similar observations have been reported in highly anxious college students, who are more likely to engage in high-risk behaviors behind the wheel (e.g., running stop signs, yelling at other drivers) than students with low or moderate levels of anxiety [15], and among fearful drivers, who are more likely to make a higher number of driving errors than nonfearful drivers [16]. Moreover, similar data have also been reported on combat Veterans. One exploratory pilot study provided evidence of a conceptual relationship between heightened anxiety, "battlemind" driver training, cognitive appraisal of a situation, and reactionary driving behaviors in post-9/11 Veterans with comorbid TBI/PTSD [17]. The authors reported three categories of driving triggers that provoke reactions from Veterans: (1) anxious driving triggers (e.g., loud noises), (2) speeding triggers (e.g., inattention), and (3) road rage triggers (e.g., getting cut off). While these findings are very useful conceptually and can inform intervention efforts, these data are limited by a small sample size $(N=$ 5) and a qualitative data collection that lacked a comparison group.

In sum, while prior studies of combat Veterans have examined cognitive function following TBI and PTSD as well as the effects of PTSD on driving, several important areas have remained relatively unexplored. First, research has primarily focused on PTSD, while few studies have assessed the effects of comorbid TBI/PTSD on driving in the Veteran population. Second, the majority of prior studies have relied on nondisabled civilians as a control group. Given the high relevance of military training and experiences in combat environments to Veterans' driving practices following military separation, civilian control subjects may not offer a truly analogous comparison group. Studies comparing combat Veterans with comorbid TBI/PTSD to nondisabled combat Veterans could provide a more refined understanding of the specific challenges Veterans face behind the wheel. Finally, previous studies have not often included driving measures specific to combat driver training and experiences nor have they focused directly on the link between heightened anxiety and driving behaviors in combat.

To address these limitations, we proposed to examine differences in driving habits of combat Veterans with comorbid TBI/PTSD compared with nondisabled combat Veterans using a measure designed to account for combat driving practices and anxiety related to combat driving experiences (e.g., encountering improvised explosive devices [IEDs]). However, a review of the literature 
revealed no measures appropriate for and sensitive to the specific experiences of post-9/11 combat Veterans. The current project therefore (1) developed and piloted a novel self-report measure, the Veteran Driving Questionnaire (VDQ), and (2) compared VDQ responses across two groups of combat Veterans, those with comorbid TBI/PTSD and those without any major psychiatric or physical diagnoses.

\section{METHODS}

This study was performed at the Corporal Michael J. Crescenz Department of Veterans Affairs (VA) Medical Center (VAMC) in Philadelphia, Pennsylvania, and it represents a collaboration with the Department of Psychology at Drexel University in Philadelphia, Pennsylvania. Data were collected in two phases: measure development and piloting.

\section{Development of the Veteran Driving Questionnaire}

A comprehensive literature search provided the theoretical foundation of the new questionnaire and helped direct specific lines of inquiry during the focus group discussions. Qualitative and quantitative peer-reviewed studies of Veteran driving habits and difficulties were searched using the key terms "Veterans," "driving," "PTSD," "brain injury," "combat," "simulator," "battlemind," and "OIF/OEF." Next, we consulted VA polytrauma clinicians in Philadelphia, including a physiatrist, a clinical neuropsychologist, and an occupational therapist, responsible for conducting driving and on-road assessments with returning Veterans. The data gained from these interviews were integrated with the findings from the literature search to develop the initial item battery for the VDQ. We decided to examine the frequency of occurrence for three dimensions of driving that were highlighted by both prior literature and VA clinicians as critical to driving performance: (1) common emotional states, (2) behind-the-wheel behaviors, and (3) anxiety as related to external roadside environments. Therefore, these three VDQ subscales were developed a priori based primarily on cognitive-behavioral theoretical frameworks of TBI, PTSD, and driving (e.g., road rage).

Following this initial developmental phase, four clinicians (a physiatrist, a neuropsychologist, an occupational therapist, and a clinical psychologist) were asked to rate each item in terms of wording and relevance to the
Veteran population. Items not rated highly were clarified or removed entirely. This analysis ensured that the new measure was adequately sensitive and relevant to the target population prior to pilot testing.

\section{Focus Groups}

Firsthand data on common high-risk driving behaviors and scenarios were solicited from post-9/11 Veterans diagnosed with comorbid combat-related TBI and PTSD. Two semistructured focus groups with a total of four participants were conducted. All focus group participants completed informed consent procedures prior to completing the VDQ. After participants completed the questionnaire, they were asked to give both verbal and written feedback on the clarity and relevance of the existing items using a standardized list of questions. Next, the participants were asked to discuss various driving situations, frustrations, and triggers. This open-ended format allowed for the introduction of several unanticipated factors that contribute to driving attitudes, such as avoiding speeding tickets through the use of a Veteran identification card and frustrations with subtle differences between civilian and military road etiquette (e.g., attention to entry/exit points at a gas station). The feedback gained from these focus groups provided a stronger context for understanding the driving environment of Veterans both in combat and in civilian life and allowed for further refinement of the VDQ.

\section{Final Structure of the Veteran Driving Questionnaire}

The final VDQ (Appendix, available online only) includes a general background section examining premilitary, combat, and postmilitary driving history. The VDQ also includes three distinctive subscales examining current driving experiences (postmilitary separation only). The first subscale, termed "situational anxiety," assesses the severity of anxiety provoked by common roadside environments and triggers (e.g., driving over potholes, driving in rush hour). The second subscale, "driving behaviors," measures the frequency of self-reported driving behaviors. Behaviors queried include both protective (e.g., use of a seatbelt or helmet) and high-risk (e.g., swerving in tunnels or overpasses) maneuvers. The final subscale, "affective states," inquires about the frequency of various emotional states experienced while driving.

\section{Veteran Driving Questionnaire Scoring}

All subscale items were measured using a five-point Likert scale. Items believed to increase driver safety 
based on available driving literature (e.g., use of seatbelt, use of a designated driver) were reverse coded, and three subscale scores for each participant were computed. Total VDQ score is the sum of the subscales. Higher scores are theorized to represent more at-risk driving.

\section{Sample}

A total of 33 participants were recruited from the polytrauma program and primary care postdeployment clinics at the Michael J. Crescenz VAMC in Philadelphia between February 2012 and March 2013. All participants had deployed to combat zones in Active Duty service of OIF and/or OEF. Ten Veterans with no major psychiatric or physical diagnoses served as nondisabled combat control subjects, and 23 Veterans had diagnoses of comorbid TBI/PTSD. Of those participants with comorbid TBI/ PTSD, 20 were diagnosed with mild TBI and 3 with moderate TBI, 10 reported blast exposure only, 3 reported blunt force trauma only, and 10 reported both blast and blunt force trauma. Of the Veterans exposed to blast, 17 of 20 reported five or more blast exposures. Additional demographic variables are reported in Table 1.

The diagnoses of TBI/PTSD were identified via chart review and verified by a polytrauma clinician (KMR) familiar with participants at the time of study enrollment. Therefore, diagnostic criteria originally used to diagnose TBI and PTSD were those generated by the VA and the Department of Defense to guide polytrauma team assessments [18-19]. Additional information regarding TBI details specifically related to convoy/driving experiences were queried during the testing session. In the interest of recruiting a generalizable sample, common comorbid conditions (e.g., chronic pain, depression, insomnia) were not considered exclusionary criteria. However, alcohol/ substance abuse and suicidal/homicidal ideation within the past $90 \mathrm{~d}$ and/or severe psychiatric history (e.g., psychosis) were grounds for exclusion, as these conditions could significantly confound driving performance.

Deployment details are reported in Table 2. Groups differed on location and dates of deployment. Veterans with TBI/PTSD primarily served in Iraq during the early years of OIF (2001-2006), prior to the introduction of heavily armored vehicles. Nondisabled control Veterans were more likely to serve in Afghanistan post-2006.

No significant group differences between nondisabled control subjects and participants with comorbid TBI/PTSD were found in days driven per week (5.0/6.2, respectively), age of licensure (17.7/17.1, respectively), or years licensed prior to deployment (3.5/4.5, respec- tively). All but four participants (two per group) endorsed driving or being in convoy frequently during deployment. Only three participants stated that they did not receive tactical driver training during their military service. Two participants with comorbid TBI/PTSD received commercial driver's licenses following military separation.

\section{RESULTS}

Reliability Analysis of the Veteran Driving Questionnaire

Split-half reliability was calculated for each VDQ subscale as well as the overall scale. All subscales were found to have acceptable reliabilities with a Cronbach alpha value of 0.96 (situational anxiety), 0.88 (driving behaviors), and 0.88 (affective states). The overall VDQ likewise showed high reliability with an alpha of 0.95 .

\section{Differences in Veteran Driving Questionnaire Total Score Between Groups}

Nonparametric analyses were used to test our hypotheses that Veterans with TBI/PTSD would report (1) more frequent high-risk driving behaviors and (2) more frequent anxiety and negative emotionality while driving than nondisabled combat Veterans (Table 3). Given the small sample size, we used exact Mann-Whitney $U$ tests, which revealed that Veterans with comorbid TBI/ PTSD (median $=171.0$ ) differed significantly from nondisabled control Veterans (median $=112.0$ ) on total VDQ score $(U=56.00, z=-2.31, p=0.02, r=-0.40)$. Veterans with comorbid TBI/PTSD (median $=62.0$ ) also reported significantly higher levels of anxiety and distress in specific driving situations than nondisabled control Veterans (median $=37.5, U=47.50, z=-2.65, p=0.01, r=$ -0.46 ) as well as significantly more frequent high-risk driving behaviors (median $=62.0$ ) than nondisabled control Veterans (median $=41.5, U=62.50, z=-2.06, p=$ $0.04, r=-0.36$ ). Groups did not significantly differ in their experiences of other affective states while driving.

\section{Exploratory Analyses}

Table 4 provides a descriptive analysis of the 10 situations rated most anxiety provoking by the overall sample, listed in descending order for those with TBI/PTSD. Table 5 explores the strength of the relationships between specific items on the VDQ across the entire sample of Veterans. Items analyzed included the most salient demographic characteristic (age) based on available driving literature, the most and least frequently endorsed 
Table 1.

Participant characteristic by group.

\begin{tabular}{|c|c|c|}
\hline Variable & TBI/PTSD $(n=23)$ & Control $(n=10)$ \\
\hline Age, yr (mean \pm SD) & $32.74 \pm 7.26$ & $28.80 \pm 4.78$ \\
\hline \multicolumn{3}{|l|}{ Sex, $n$} \\
\hline Male & 22 & 10 \\
\hline Education, yr (mean \pm SD) & $15.39 \pm 1.95$ & $13.40 \pm 2.32^{*}$ \\
\hline Duration of Military Separation, mo (mean \pm SD) & $62.96 \pm 28.90$ & $23.70 \pm 23.45^{\dagger}$ \\
\hline Right & 17 & 10 \\
\hline \multicolumn{3}{|l|}{ Race $(\%)^{\ddagger}$} \\
\hline African American & 30 & 40 \\
\hline Asian & 4 & 0 \\
\hline Caucasian & 52 & 60 \\
\hline Divorced & 13 & 10 \\
\hline \multicolumn{3}{|l|}{ Employment Status (\%) } \\
\hline Full-Time & 30 & 20 \\
\hline Part-Time & 4 & 0 \\
\hline Unemployed & 39 & 50 \\
\hline Student & 26 & 30 \\
\hline \multicolumn{3}{|l|}{ Branch of Military (\%) } \\
\hline Air Force & 9 & 0 \\
\hline Army/Army National Guard & 65 & 80 \\
\hline Navy & 9 & 10 \\
\hline
\end{tabular}

behaviors on the VDQ, and the most and least frequently endorsed affective states. Notably, age was not strongly related to speeding $(r=0.14)$, and feelings of anxiety and control were negatively correlated $(r=-0.45)$.

\section{DISCUSSION}

Combat Veterans diagnosed with comorbid TBI/ PTSD and nondisabled combat Veteran control subjects completed a novel driving questionnaire designed to mea- sure the frequency of self-reported anxiety, safe/high-risk behaviors, and adaptive/maladaptive affective states experienced while driving. Though these data are preliminary, we found that Veterans with comorbid TBI/PTSD reported higher levels of anxiety in most driving situations and more frequent high-risk driving behaviors than control Veterans but did not differ in frequency of other adaptive/maladaptive affective states. The situations rated most anxiety provoking are reminiscent of combat driving environments and therefore may result in the misinterpretation of common, generally unthreatening roadside 
Table 2.

Participant deployment details.

\begin{tabular}{lrc}
\hline \multicolumn{1}{c}{ Variable } & $\begin{array}{c}\text { TBI/PTSD } \\
(\boldsymbol{n}=\mathbf{2 3})\end{array}$ & $\begin{array}{c}\text { Control } \\
(\boldsymbol{n}=\mathbf{1 0})\end{array}$ \\
\hline Combat Theater (\%) $^{*}$ & 78 & 30 \\
$\quad$ Iraq & 0 & 50 \\
Afghanistan & 22 & 20 \\
$\quad$ Both Iraq and Afghanistan & & \\
Date Range of Deployment(s) (\%) & 70 & 20 \\
2001-2006 & 4 & 70 \\
2006-2013 & 26 & 10 \\
2001-2013 & & \\
Convoy Vehicle (\%) ${ }^{\dagger}$ & 65 & 30 \\
Unarmored (HMMWV, HEMTT, Jeep) & 17 & 40 \\
Armored (MRAP, Stryker) & 17 & 30 \\
Other/Unknown (Van, Semitruck) & & \\
Primary Position in Convoy (\%) & 35 & 30 \\
Driver & 13 & 30 \\
Gunner & 13 & 20 \\
Passenger (Squad Leader/Truck Commander) & 30 & 0 \\
Driver and Gunner (50/50) & 9 & 20 \\
Not in Convoy &
\end{tabular}

${ }^{*} p<0.01$ (Pearson chi-square, $\chi^{2}<0.01$ ).

${ }^{\dagger}$ Percentages are calculated within each diagnostic group and in some cases do not add up to $100 \%$ because data are rounded to the nearest whole number.

HEMTT = heavy expanded mobility tactical truck, HMMWV = highmobility multipurpose wheeled vehicle, MRAP = mine-resistant ambush protected vehicle, $\mathrm{PTSD}=$ posttraumatic stress disorder, $\mathrm{TBI}=$ traumatic brain injury.

stimuli in civilian environments. Taken together, these data suggest that Veterans with comorbid TBI/PTSD may selectively attend to, interpret, and respond to roadside environments and events differently than nondisabled Veterans, leading to more subjective anxiety and greater risk-taking behind the wheel. For example, being boxed in and driving next to or over debris and potholes are often high-risk situations in modern combat scenarios, and personnel deployed to OIF/OEF/OND combat theaters were trained to expect ambushes from those cues.
Given that the two groups in our sample had similar military driving training and demographic traits predeployment, it is likely that the combat-relevant situations are most distressing to those with comorbid TBI/PTSD because they have more difficulty differentiating between combat and civilian driving experiences after military separation. Driving anxiety as reported here has been hypothesized by other investigators to be constantly reinforced through a cycle of fear and avoidance, as discussed by Possis et al. [11], leading to long-term anxiety maintenance.

Our preliminary observations are supported by prior literature on attentional allocation and information processing biases. Individuals with PTSD are often limited in capacity for divided attention, more easily distracted by competing stimuli, and cognitively biased toward attending to trauma-relevant stimuli [20]. Individuals with TBI may show impaired attentional control and difficulty responding adaptively to a variety of complex situations, such as driving [21]. Therefore, a combination of insufficient or biased attentional control, negative event interpretation, impaired response selection, and conditioned fear may lead to heightened negative emotionality while driving for Veterans with comorbid TBI/PTSD, particularly in environments laden with combat-salient stimuli (e.g., trash on the side of the road).

Several of our findings are consistent with previous research. Many of the high-risk behaviors endorsed by our sample (e.g., speeding, accelerating through yellow lights, becoming easily distracted by sights and sounds) have been reported in prior studies on Veterans [2,14]. However, several protective behaviors were also highly endorsed by this sample (e.g., wearing a seatbelt or helmet, using a designated driver), and this finding is somewhat curious. Previous research has shown that combat Veterans of the Gulf Wars and OIF/OEF conflicts are less

Table 3.

Subscale and overall Veteran Driving Questionnaire (VDQ) scores by group.

\begin{tabular}{|c|c|c|c|c|c|}
\hline VDQ & $\begin{array}{c}\text { TBI/PTSD }(n=23) \\
\text { Mean } \pm \text { SD }\end{array}$ & $\begin{array}{c}\text { Control }(n=10) \\
\text { Mean } \pm \text { SD }\end{array}$ & $\boldsymbol{U}$ & $\mathbf{Z}$ & $\boldsymbol{r}$ \\
\hline Situational Anxiety & $62.43 \pm 14.52$ & $39.50 \pm 23.36$ & $47.50^{*}$ & -2.65 & -0.46 \\
\hline Driving Behaviors & $56.04 \pm 18.54$ & $43.40 \pm 13.56$ & $62.50^{\dagger}$ & -2.06 & -0.36 \\
\hline Overall Score & $161.83 \pm 38.48$ & $120.90 \pm 44.45$ & $56.00^{\dagger}$ & -2.31 & -0.40 \\
\hline
\end{tabular}


Table 4.

Situational anxiety subscale: Individual Veteran Driving Questionnaire items rated most anxiety provoking.

\begin{tabular}{lcc}
\multicolumn{1}{c}{ Anxiety-Producing Situations } & $\begin{array}{c}\text { TBI/PTSD } \\
\text { Mean } \pm \text { SD (\%) }\end{array}$ & $\begin{array}{c}\text { Montrol } \\
\text { Mean } \pm \text { SD (\%) }\end{array}$ \\
\hline Boxed in by Other Cars & $3.57 \pm 0.73(87)$ & $2.22 \pm 1.39(44)$ \\
Approached Quickly from Behind & $3.39 \pm 0.89(83)$ & $2.90 \pm 1.52(80)$ \\
Roadside Debris & $3.35 \pm 1.03(83)$ & $1.56 \pm 1.33(22)$ \\
Tight or Narrow Lanes & $3.13 \pm 1.01(74)$ & $2.40 \pm 1.26(50)$ \\
Slow or Stopped Traffic & $3.09 \pm 0.90(65)$ & $2.10 \pm 1.10(40)$ \\
Driving over Potholes & $3.09 \pm 0.85(70)$ & $1.80 \pm 1.32(30)$ \\
Driving When Lost & $2.96 \pm 1.02(56)$ & $2.11 \pm 1.05(20)$ \\
Person-Crowded Area & $2.91 \pm 1.00(65)$ & $1.90 \pm 1.29(30)$ \\
Glare from Sunlight/Headlights & $2.83 \pm 1.03(56)$ & $2.30 \pm 1.25(60)$ \\
Limited Visibility & $2.57 \pm 1.16(52)$ & $2.70 \pm 1.34(70)$ \\
Note: The mean and SD represent scores within group from 1 (never anxious) to 5 (always anxious); percentages = respondents endorsing a 4 (frequently anxious) \\
or a 5 (always anxious).
\end{tabular}

Table 5.

Correlations between individual items on the Veteran Driving Questionnaire.

\begin{tabular}{lcccccccc}
\multicolumn{1}{c}{ Item } & Age & Speed & DUI & Careful Eye & Avoid & Anxious & Confident & Vigilant \\
\hline Age & 1 & - & - & - & - & - & - & - \\
Speed & 0.14 & 1 & - & - & - & - & - \\
DUI & -0.05 & 0.19 & 1 & - & - & - & - \\
Careful Eye & 0.18 & 0.07 & 0.11 & 1 & - & - & - \\
Avoid & 0.23 & 0.32 & 0.01 & 0.20 & 1 & - & - \\
Anxious & 0.06 & 0.18 & 0.10 & $0.59^{*}$ & 0.21 & 1 & - \\
Confident & 0.23 & 0.06 & 0.15 & 0.06 & -0.14 & -0.15 & - \\
Vigilant & 0.06 & -0.21 & -0.01 & $0.60^{*}$ & 0.06 & 0.20 & 0.24 \\
In Control & 0.15 & 0.15 & 0.23 & -0.13 & -0.13 & $-0.45^{*}$ & $0.62^{*}$ & 0.05 \\
\hline
\end{tabular}

${ }^{*}$ Correlation significant at the 0.01 level.

DUI $=$ driving under the influence.

likely to wear seatbelts and more likely to drive intoxicated than noncombat Veterans [8,22-23]. However, this discrepancy may be explained by self-report bias or by measurement artifact. Few prior studies directly probed protective behaviors in addition to high-risk driving habits; moreover, much of the prior data on driving characteristics of combat Veterans are drawn from crash fatality and injury statistics [22-23].

Regarding affective states beyond anxiety, several of our findings are inconsistent with expectations based on prior literature. Jakupcak et al. [24] found that Iraq and Afghanistan Veterans with PTSD reported greater aggression, anger, and hostility than Veterans without PTSD, while Lew et al. [14] reported that 82 percent of OIF/OEF Veterans seen in a polytrauma clinic most frequently endorsed anger and impatience as their primary area of difficulty on the road. While this study subse- quently hypothesized similar findings, this sample did not highly endorse anger on the road (only $21 \%$ endorsed very frequent anger), suggesting that "anger" may be too strong a term. Instead, milder but frequent episodes of impatience, irritability, and frustration are reported more commonly in our sample, with similar frequency across groups. Qualitatively, the Veterans sampled in this study were aware of their anger triggers and had developed cognitive and behavioral strategies for reducing their own emotional reactivity while driving. Therefore, the presence of these milder emotions in place of stronger reactions (e.g., road rage) may be attributable to the participants' having already developed coping strategies after deployment (e.g., avoiding certain driving environments). Additionally, impulsivity, recklessness, irresponsibility, and feelings of invincibility while driving were 
endorsed least frequently in this study, which is in contrast to the majority of driving studies on Veterans $[3,5]$.

One possible reason for this is that the current study sample separated from the military less recently (on average almost $63 \mathrm{mo}$ ) than samples observed in other studies. For example, Killgore et al. assessed risk-taking propensity in soldiers 3 mo after they returned from Iraq [5]. Another explanation is that our sample is older (mean = $31.5 \mathrm{yr}$ ) than in other studies observing Veteran risk-taking propensity $[2,5]$.

A final consideration is that both groups in this study consisted of combat Veterans rather than one group, the control group, consisting of civilians or noncombat Veterans as is common in other studies. A "balancing out" induced by similarities between the two Veteran groups may have occurred in this study. It may therefore be the case that both groups would appear more risk-prone while driving when compared with nondisabled civilians because these driving behaviors are an idiosyncratic trait of the Veteran population.

Finally, the initial implementation of this questionnaire highlighted the uncertain distinction between highrisk and protective behaviors in anxious or cognitively impaired populations, particularly in terms of environmental control strategies. Several items assessed on the VDQ were qualitatively reported by participants as either reasonable and protective or distressing and impairing. Despite our classification of protective versus high-risk items, this distinction appears to depend on the Veteran's perception of his or her reasons for engaging in these habits, and the subjective experience of our sample was inconsistent across individuals regarding behaviors as safe/protective versus functionally impairing/dangerous. For example, "keeping a careful eye on other cars" and "planning to avoid anxiety-provoking situations" were endorsed at similar rates by both groups. Participants with comorbid TBI/PTSD anecdotally reported substantial frustration and impairment resulting from these hypervigilant and avoidant behaviors, while control participants considered these habits to be logical and protective. Moreover, several control participants reported that military training actually improved their driving habits because they became more aware of their surroundings and more technically skilled, while drivers with comorbid TBI/PTSD more often reported feeling overly stimulated on the road, resulting in both poorer driving and driving avoidance. Thus, driving quantifiers such as "awareness" and "avoidance" are not inherently protec- tive or high risk. Instead, the distinction may be dependent on the individual's perception of his or her own control over the behavior as well as its functional consequences (e.g., loss of vocational opportunities).

\section{Limitations}

The generalization of this study to the broader population of returning OIF/OEF/OND combat Veterans with comorbid TBI/PTSD is limited by the small sample size, the specific demographic traits of our sample, and the parochial necessity of Veteran recruiting. Recall and selfreport biases and TBI/PTSD-related memory inaccuracies may have influenced participant responses, and we did not independently assess for adequate effort on the selfreport measure. The novelty of the VDQ further limits the interpretation of the current findings in that its psychometric properties have not yet been firmly established. However, this measure does appear to be successful in exploring a basic description of common and relevant triggers of anxiety in this specific population.

Preexisting group differences also limit the interpretation of these data. The majority of our Veterans with comorbid TBI/PTSD served in Iraq and separated from the military several years ago. Following separation, this earlier cohort often pursued higher education before or instead of entering the workforce. In contrast, our nondisabled combat Veterans primarily served in the later years of the war in Afghanistan and separated from the military more recently, restricting their ability to pursue additional education. Consequently, educational achievement partially functions as a proxy for time since military separation in this sample. It is not certain how these group differences affect Veterans' perceptions of driving.

While comorbid TBI/PTSD is common in this combat cohort and our sample is representative of the broader polytrauma population, single-diagnosis comparison groups would add necessary data to the literature. Future research should focus on comparing individuals with comorbid TBI/PTSD to those with only PTSD, should be prospective, and should include informant validation of Veterans' self-reported driving behaviors. It would be particularly informative to follow a cohort of Veterans after it returns home from deployment in order to capture adaptation in civilian driving habits over time.

\section{Future Directions}

An important factor not previously considered in this line of research is that Veterans' driving habits may be 
influenced more by deployment location and timeframe than by mental health symptoms. Our participants' heterogeneity in combat driving experiences strongly depended on year deployed and the specific combat theater the Veteran experienced. Armored vehicle technology, combat driving protocols, roadside terrain, and IEDs all evolved dramatically over the past decade. Veterans who deployed to Iraq in the early/mid-2000s were generally taught to drive fast, nonstop, and erratically to avoid ambushes and push cars or blockades out of the way. Conversely, Veterans who deployed in the later years of OIF/OEF were generally trained to drive slowly and carefully, often with the purpose of hunting for IEDs. The latter cohort utilized heavily armored vehicles designed to protect against roadside IEDs, and this difference in technology drastically affected convoy procedures. As discussed previously, our participants with comorbid TBI/PTSD primarily served in Iraq prior to the 2007 introduction of armored fighting vehicles, and it cannot be determined how much this difference in combat driving tactics may have influenced our data. Future research on this topic should therefore incorporate this aspect more carefully into study design.

In general, future research should aim to understand the relationship among roadside stimuli, anxiety, and reactionary behaviors (particularly avoidance) in order to design targeted interventions and treatment options. In a clinical setting, Veterans with driving anxiety may need to learn new strategies for effectively managing their arousal and reformulating their cognitive processing patterns. An inability to safely process the negative emotionality and heightened anxiety that occur with both TBI and PTSD can have significant and potentially fatal implications while driving.

\section{CONCLUSIONS}

The current exploratory pilot study is, to the best of our knowledge, the first to compare the frequency of selfreported driving behaviors, situational anxiety, and negative emotionality in combat Veterans with comorbid TBI/ PTSD with nondisabled Veterans with similar combat driving experiences. We found that Veterans with comorbid TBI/PTSD overall report a much higher level of anxiety in certain driving situations and more frequent highrisk driving behaviors than nondisabled combat Veterans. These preliminary findings support the postulation that the post-9/11 Veteran population demonstrates a specific pattern of driving-related anxiety and performance that may not be found in other populations given the distinctive prevalence of comorbid TBI/PTSD. It is possible that this pattern of difficulties may be linked to stimuli in civilian driving environments that cue combat recollections and trigger excessive arousal. Specific combat exposure factors (e.g., deployment location and year, time spent in convoy) are speculated to have distinctive effects on post-9/11 Veterans' driving habits.

\section{ACKNOWLEDGMENTS}

\section{Author Contributions:}

Study concept and design: E. K. Whipple, M. T. Schultheis, K. M. Robinson.

Acquisition of data: E. K. Whipple.

Statistical analysis and interpretation of data: E. K. Whipple,

M. T. Schultheis, K. M. Robinson.

Drafting of manuscript: E. K. Whipple.

Critical revision of manuscript for important intellectual content:

M. T. Schultheis, K. M. Robinson.

Obtained funding: E. K. Whipple.

Administrative, technical, or material support: M. T. Schultheis, K. M. Robinson.

Study supervision: M. T. Schultheis, K. M. Robinson.

Financial Disclosures: The authors have declared that no competing interests exist.

Funding/Support: This material was based on work supported by the Council on Brain Injury (grant \#260472).

Additional Contributions: We thank Delores Iacovone, Rosette Biester, and Evan Forman for their guidance, which greatly improved research methodology and measure development.

Institutional Review: This study was approved by the institutional review board at the Corporal Michael J. Crescenz VAMC in Philadelphia, Pennsylvania. All participants provided written informed consent. Participant Follow-Up: The authors do not plan to inform all participants of the publication of this study; however, participants still receiving clinical care within the Corporal Michael J. Crescenz VAMC will be provided a copy of this publication upon request.

\section{REFERENCES}

1. Classen S, Levy C, Meyer DL, Bewernitz M, Lanford DN, Mann WC. Simulated driving performance of combat veterans with mild traumatic brain injury and posttraumatic stress disorder: A pilot study. Am J Occup Ther. 2011; 65(4):419-27. [PMID:21834457]

http://dx.doi.org/10.5014/ajot.2011.000893

2. Fear NT, Iversen AC, Chatterjee A, Jones M, Greenberg N, Hull L, Rona RJ, Hotopf M, Wessely S. Risky driving 
among regular armed forces personnel from the United Kingdom. Am J Prev Med. 2008;35(3):230-36. [PMID:18617356] http://dx.doi.org/10.1016/j.amepre.2008.05.027

3. Kuhn E, Drescher K, Ruzek J, Rosen C. Aggressive and unsafe driving in male veterans receiving residential treatment for PTSD. J Trauma Stress. 2010;23(3):399-402. [PMID:20564373]

4. Zinzow HM, Brooks J, Stern EB. Driving-related anxiety in recently deployed service members: Cues, mental health correlates, and help-seeking behavior. Mil Med. 2013;178(3): e357-61. [PMID:23707125] http://dx.doi.org/10.7205/MILMED-D-12-00303

5. Killgore WD, Cotting DI, Thomas JL, Cox AL, McGurk D, Vo AH, Castro CA, Hoge CW. Post-combat invincibility: Violent combat experiences are associated with increased risk-taking propensity following deployment. J Psychiatr Res. 2008;42(13):1112-21. [PMID:18291419] http://dx.doi.org/10.1016/j.jpsychires.2008.01.001

6. Amick MM, Kraft M, McGlinchey R. Driving simulator performance of veterans from the Iraq and Afghanistan Wars. J Rehabil Res Dev. 2013;50(4):463-70. [PMID:23934867] http://dx.doi.org/10.1682/JRRD.2012.06.0108

7. Kraft M, Amick MM, Barth JT, French LM, Lew HL. A review of driving simulator parameters relevant to the Operation Enduring Freedom/Operation Iraqi Freedom veteran population. Am J Phys Med Rehabil. 2010;89(4):336-44. [PMID:20299851] http://dx.doi.org/10.1097/PHM.0b013e3181d3eb5f

8. Sayer NA, Noorbaloochi S, Frazier P, Carlson K, Gravely A, Murdoch M. Reintegration problems and treatment interests among Iraq and Afghanistan combat veterans receiving VA medical care. Psychiatr Serv. 2010;61(6): 589-97. [PMID:20513682] http://dx.doi.org/10.1176/ps.2010.61.6.589

9. Ilie G, Mann RE, Ialomiteanu A, Adlaf EM, Hamilton H, Wickens CM, Asbridge M, Rehm J, Cusimano MD. Traumatic brain injury, driver aggression and motor vehicle collisions in Canadian adults. Accid Anal Prev. 2015;81:1-7. [PMID:25935425] http://dx.doi.org/10.1016/j.aap.2015.04.021

10. Schultheis MT, Whipple E. Driving after traumatic brain injury: Evaluation and rehabilitation interventions. Curr Phys Med Rehabil Rep. 2014;2(3):176-83.

[PMID:25436178]

http://dx.doi.org/10.1007/s40141-014-0055-0

11. Possis E, Bui T, Gavian M, Leskela J, Linardatos E, Loughlin J, Strom T. Driving difficulties among military veterans: Clinical needs and current intervention status. Mil Med. 2014;179(6):633-39. [PMID:24902130] http://dx.doi.org/10.7205/MILMED-D-13-00327
12. Uddo M, Vasterling JJ, Brailey K, Sutker PB. Memory and attention in combat-related post-traumatic stress disorder (PTSD). J Psychopathol Behav Assess. 1993;15(1):43-52. http://dx.doi.org/10.1007/BF00964322

13. Buckley TC, Blanchard EB, Hickling EJ. Automatic and strategic processing of threat stimuli: A comparison between PTSD, panic disorder, and nonanxiety controls. Cognit Ther Res. 2002;26(1):97-115. http://dx.doi.org/10.1023/A:1013897805918

14. Lew HL, Kraft M, Pogoda TK, Amick MM, Woods P, Cifu DX. Prevalence and characteristics of driving difficulties in Operation Iraqi Freedom/Operation Enduring Freedom combat returnees. J Rehabil Res Dev. 2011;48(8):913-25. [PMID:22068370] http://dx.doi.org/10.1682/JRRD.2010.08.0140

15. Dula CS, Adams CL, Miesner MT, Leonard RL. Examining relationships between anxiety and dangerous driving. Accid Anal Prev. 2010;42(6):2050-56. [PMID:20728661] http://dx.doi.org/10.1016/j.aap.2010.06.016

16. Taylor JE, Deane FP, Podd JV. Driving fear and driving skills: Comparison between fearful and control samples using standardised on-road assessment. Behav Res Ther. 2007;45(4): 805-18. [PMID:16962560] http://dx.doi.org/10.1016/j.brat.2006.07.007

17. Hannold EM, Classen S, Winter S, Lanford DN, Levy CE. Exploratory pilot study of driving perceptions among OIF/ OEF Veterans with mTBI and PTSD. J Rehabil Res Dev. 2013;50(10):1315-30. [PMID:24699968] http://dx.doi.org/10.1682/JRRD.2013.04.0084

18. Management of Concussion/mTBI Working Group. VA/ DoD clinical practice guideline for management of concussion/mild traumatic brain injury. J Rehabil Res Dev. 2009; 46(6):CP1-68. [PMID:20108447]

19. Management of Post-Traumatic Stress Working Group. VA/DoD clinical practice guideline for management of post-traumatic stress, V2.0 [Internet]. Washington (DC): Veterans Health Administration and the Department of Defense; 2010 [cited 2016 Oct 6]. 252 p. Available from: http://www.healthquality.va.gov/guidelines/MH/ptsd/ cpg_PTSD-full-201011612.PDF

20. Danckwerts A, Leathem J. Questioning the link between PTSD and cognitive dysfunction. Neuropsychol Rev. 2003; 13(4):221-35. [PMID:15000227] http://dx.doi.org/10.1023/B:NERV.0000009485.76839.b7

21. Campbell TA, Nelson LA, Lumpkin R, Yoash-Gantz RE, Pickett TC, McCormick CL. Neuropsychological measures of processing speed and executive functioning in combat veterans with PTSD, TBI, and comorbid TBI/PTSD. Psychiatr Ann. 2009;39(8):796-803. http://dx.doi.org/10.3928/00485713-20090728-01

22. Bell NS, Amoroso PJ, Wegman DH, Senier L. Proposed explanations for excess injury among veterans of the Persian 
Gulf War and a call for greater attention from policymakers and researchers. Inj Prev. 2001;7(1):4-9.

[PMID:11289533]

http://dx.doi.org/10.1136/ip.7.1.4

23. Lincoln AE, Hooper TI, Kang HK, Debakey SF, Cowan DN, Gackstetter GD. Motor vehicle fatalities among Gulf War era veterans: Characteristics, mechanisms, and circumstances. Traffic Inj Prev. 2006;7(1):31-37.

[PMID:16484030]

http://dx.doi.org/10.1080/15389580500412028

24. Jakupcak M, Conybeare D, Phelps L, Hunt S, Holmes HA, Felker B, Klevens M, McFall ME. Anger, hostility, and aggression among Iraq and Afghanistan War veterans reporting PTSD and subthreshold PTSD. J Trauma Stress. 2007;20(6):945-54. [PMID:18157891]

http://dx.doi.org/10.1002/jts.20258
Submitted for publication September 8, 2015. Accepted in revised form April 13, 2016.

This article and any supplementary material should be cited as follows:

Whipple EK, Schultheis MT, Robinson KM. Preliminary findings of a novel measure of driving behaviors in Veterans with comorbid TBI and PTSD. J Rehabil Res Dev. 2016;53(6): 827-38.

http://dx.doi.org/10.1682/JRRD.2015.09.0172

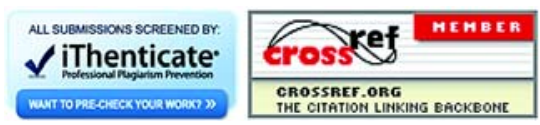


